University of Nebraska - Lincoln

DigitalCommons@University of Nebraska - Lincoln

CSE Journal Articles

Computer Science and Engineering, Department of

2014

\title{
Autonomous Capabilities for Small Unmanned Aerial Systems Conducting Radiological Response: Findings from a High-fidelity Discovery Experiment
}

Brittany Duncan

University of Nebraska-Lincoln, bduncan@unl.edu

Robin Murphy

Texas Aઐ'M University, murphy@cse.tamu.edu

Follow this and additional works at: http://digitalcommons.unl.edu/csearticles

Part of the Aeronautical Vehicles Commons, Aviation Commons, Navigation, Guidance, Control and Dynamics Commons, and the Operations Research, Systems Engineering and Industrial Engineering Commons

Duncan, Brittany and Murphy, Robin, "Autonomous Capabilities for Small Unmanned Aerial Systems Conducting Radiological Response: Findings from a High-fidelity Discovery Experiment" (2014). CSE Journal Articles. 135.

http://digitalcommons.unl.edu/csearticles/135

This Article is brought to you for free and open access by the Computer Science and Engineering, Department of at DigitalCommons@University of Nebraska - Lincoln. It has been accepted for inclusion in CSE Journal Articles by an authorized administrator of DigitalCommons@University of Nebraska - Lincoln. 


\title{
Autonomous Capabilities for Small Unmanned Aerial Systems Conducting Radiological Response: Findings from a High-fidelity Discovery Experiment
}

\author{
Brittany A. Duncan and Robin R. Murphy \\ Center for Robot-Assisted Search and Rescue, Texas A\&M University, College Station, TX 77843
}

\begin{abstract}
This article presents a preliminary work domain theory and identifies autonomous vehicle, navigational, and mission capabilities and challenges for small unmanned aerial systems (SUASs) responding to a radiological disaster. Radiological events are representative of applications that involve flying at low altitudes and close proximities to structures. To more formally understand the guidance and control demands, the environment in which the SUAS has to function, and the expected missions, tasks, and strategies to respond to an incident, a discovery experiment was performed in 2013. The experiment placed a radiological source emitting at 10 times background radiation in the simulated collapse of a multistory hospital. Two SUASs, an AirRobot 100B and a Leptron Avenger, were inserted with subject matter experts into the response, providing high operational fidelity. The SUASs were expected by the responders to fly at altitudes between 0.3 and $30 \mathrm{~m}$, and hover at $1.5 \mathrm{~m}$ from urban structures. The proximity to a building introduced a decrease in GPS satellite coverage, challenging existing vehicle autonomy. Five new navigational capabilities were identified: scan, obstacle avoidance, contour following, environment-aware return to home, andreturn to highest reading. Furthermore, the data-to-decision process could be improved with autonomous data digestion and visualization capabilities. This article is expected to contribute to a better understanding of autonomy in a SUAS, serve as a requirement document for advanced autonomy, and illustrate how discovery experimentation serves as a design tool for autonomous vehicles.
\end{abstract}

\section{Introduction}

This article presents a preliminary work domain theory (Vicente, 1999) and identifies autonomous capabilities needed by small unmanned aerial systems (SUASs) responding to a radiological disaster. As a work domain theory is formative, that is, it captures the key elements of a new tool or protocol, it contributes new questions and environmental constraints for the research community, prioritizes capabilities to be added by manufacturers, and helps practitioners understand the current state of the art of SUASs in near-Earth, low-altitude applications. Radiological sensing requires SUASs to fly as close to the source as possible because measurable radiation decreases with the square of the distance, thus they must operate at low altitudes and near structures. However, the only known use of SUAVs for an actual radiological event was the use of the Honeywell T-Hawk at the 2011 Fukushima nuclear accident, and the autonomous capabilities of the platform were not activated (Murphy, 2014). As a result, there is no domain theory specifying the expected guidance and control demands; the types of obstacles and terrains that are associated with a radiological disaster; the missions, flight paths, altitudes and proximities, and general strategies for localizing the source of the radiation; and the expected availability of GPS and wireless connectivity.

This paper derives the work domain theory for autonomy based on the 2013 Summer Institute held at the
TexasA\&MEngineering Extension Service's Disaster City ( $)$ complex. Disaster City ${ }^{\circledR}$ is a collection of buildings, rubble, and trains accurately replicating damage to major urban structures. The Summer Institute conducted high fidelity concept experimentation with subject matter experts (SMEs) from Texas Task Force 1 (TX-TF1), Texas National Guard's 6th Weapons of Mass Destruction Civil Support Team (CST), and the Texas Commission on Environmental Quality (TCEQ), which is the state environmental protection agency. Experimenters hid a Cesium-137 radiological source emitting at 10 times the background radiation in a collapsed three-story building to simulate a leak in a nuclear medicine ward in a major hospital after an earthquake. Two different rotorcraft-a single rotor $1.5 \mathrm{~m}$ helicopter and a micro quadrotorwere used to fly missions at realistic standoff distances and conditions, providing a diversity of UAS platforms. An unmanned ground vehicle was used independently to locate the source (Duckworth, Shrewsbury, and Murphy, 2013); however, that effort is beyond the scope of this article.

A goal of the concept experimentation was to identify the autonomous capabilities needed for a SUAS response to a radiological event. In particular, the experimentation addressed three questions:

What are the missions that SUASs will be expected to conduct? What are are the tasks that comprise 
these missions and the strategies that SUASs can use to accomplish them? What is the sociotechnical organization of a radiological response and how does that impact the need for, and types of, autonomous capabilities?

This article uses the definition and categories of autonomy from the recent Defense Science Board study on the role of autonomy in Department of Defense systems (Murphy and Shields, 2012). Following the study, autonomy is viewed as a set of capabilities that enable the humanmachine system to accomplish a mission. Autonomous capabilities for unmanned systems will generally fall into one of three categories: vehicle autonomy, such as hovering and healthmonitoring; navigational autonomy, such as obstacle avoidance and path planning; and mission autonomy, including situation awareness aids, data digestion, and visualization.

The article is organized as follows. The relatively small volume of related work in unmanned systems for radiological events, either actual deployments or simulations, is reviewed in Section 2. Background information necessary for the understanding of the remainder of the paper is presented in Section 3. Section 4 describes the 2013 Summer Institute, which hosted the discovery experiment. This section describes the discovery experiment process and how it is designed to work with SMEs to identify new mission capabilities, the staging of the experiment at Disaster City $R_{\lrcorner}$, the propositions being explored, the robots used, and the flights for each of the two missions. Section 5 reports on the cognitive work analysis used to capture the missions and operational envelope for the robots that provide the ecology for autonomy, the tasks that could be conducted autonomously and the strategies for those tasks, and the sociotechnical organizational constraints on autonomy. Section 6 discusses the implications for autonomy in terms of the vehicle, navigational, and mission autonomy, and the findings are summarized in Section 7.

\section{Related Work}

The use of SUASs for radiological events has served as motivation for papers exploring some aspect of UAS swarms, such as maintaining wireless connectivity (Goddemeier, Daniel, and Wietfeld, 2012) or tracking a moving radiological source (Ristic, Morelande, Gunatilaka, and Rutten, 2007). It appears that only one SUAS has been engaged in an actual response to such an event, namely the Fukushima nuclear accident. Two theoretical papers project tasks and human-robot interaction that will be confirmed by the Summer Institute. Together the prior work suggests three tasks: radiological survey, radiation source localization, and perimeter detection.
The only known use of a SUAS for an actual radiological event was at the 2011 Fukushima nuclear accident (Murphy, 2014). Two Honeywell T-Hawk unmanned aerial vehicles were used for approximately 40 missions from April 10, 2011, to the end of July, 2011, in order to conduct radiological surveys, visual damage assessment for structural integrity monitoring, and debris removal forecasts. The longest flightwas about 1.6 $\mathrm{km}$ oneway. While theUAV use is considered sensitive information and has not been published by the Tokyo Electric Company, some details have been released or were recorded by Murphy, who designed the team protocols. The T-Hawk is a ducted fan weighing $8 \mathrm{~kg}$ without fuel. It has a range of up to $10 \mathrm{kmand}$ a speed of $20.5 \mathrm{~m} / \mathrm{s}$ (40 knots) with an endurance of up to $50 \mathrm{~min}$. The T-Hawk has a camera and forward-looking infrared (FLIR) payload but no radiological sensor. Instead, a small gamma dosimeter was attached and matched to the vehicle's GPS location for given time stamps. The robot had vehicle and navigational autonomy capabilities, but it relied heavily on human-robot teaming. The Honeywell pilots turned the autonomy off so as to be sure that they were aware of all commands being given to the robot, and thus any deviations from commanded position would be due to the wind or radiologically induced degradation of the system. The primary tasks were visual and radiological surveys, where the T-Hawk flew over the four reactor buildings at a fixed altitude and at one point hovered within a plume of smoke expected to be laden with radioactive particles. The initial survey showed that the projected radiation was less in some areas than expected, so that the SUAS team was allowed to move the SUAS heliport closer to the reactor buildings.

The work on human swarm intelligence by Bashyal and Venayagamoorthy (Bashyal and Venayagamoorthy, 2008) simulates a radiological event in MATLAB and has two attributes that relate to findings from the Summer Institute. It proposes human-machine teaming, or human-robot interaction, where the user guides the swarm to areas of interest, rather than relying on all aspects of a flight being autonomous, from path planning to navigation. It also explores a particle swarm optimization algorithm for radiation source localization, where the PSO creates a dense radiological map from which a human can then visually extract the location of highest radiation.

Clark and Fierro (2005) frame radiological detection as a perimeter detection task, not as a radiation source localization task, for a set of unmanned ground vehicles. As will be discussed later, the Summer Institute exercise saw the responders use one of the SUAVs for an initial perimeter detection followed by a survey within the perimeter within the same flight.

Typical applications of chemical plume or pollution monitoring have historically been seen as either a single robot, single task application, as in Russell, 


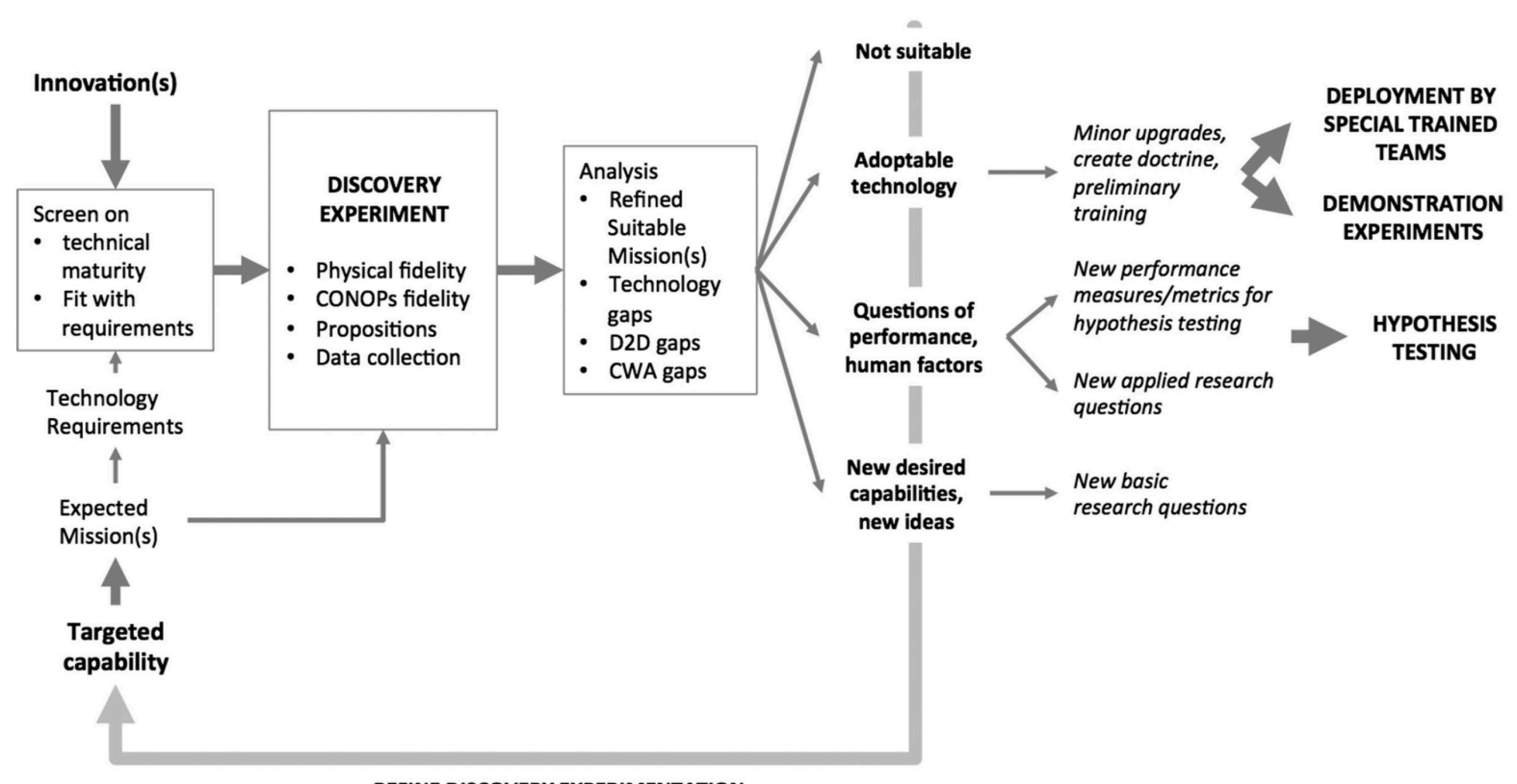

REFINE DISCOVERY EXPERIMENTATION

Figure 1. The discovery experimentation process from innovation to mission capability.

Thiel, Devesa, andMackay-Sim (1995) and Ishida, Nakayama, Nakamoto, and Moriizumi (2005), or a swarm application, single task, as in Zarzhitsky, Spears, and Spears (2005). In contrast, this exercise considers the need for the robot to be used for multiple tasks, including initial reconnaissance, source detection, and source localization. A nuclear forensics scenario also assumes the need for quick assessment, rather than a loiter-andobserve approach as in monitoring applications.

\section{Summer Institute}

The 2013 Emergency Informatics Summer Institute, June 4-7, 2013, was the fifth held by Texas A\&M, though the concept originated with Murphy in Murphy (2004), Gage, Murphy, and Minten (2004), and Murphy, Burke, and Stover (2006), and it was held annually at different locations until 2009. The Summer Institute approach to bringing together practitioners, researchers, and industry in high-fidelity exercises to foster and document innovation was formalized byWoods inWoods and Hollnagel (2006). The research objective of the Summer Institute is to conduct discovery experimentation. Discovery experimentation is a phase in a concept experimentation campaign (Alberts and Hayes, 2002) to create a newmission capability that can be adopted by the end user. Discovery experimentation is conducted in the highest possible physical and operational fidelity with SMEs in order to establish the reliability of the technology and the human-machine system performance. The radiological experiment simulated the collapse of a hospital with a large nuclear medicine wing from an earthquake. The intent was to examine technologies that could (i) speed up the initial survey of the level of radiation in the area and (ii) locate the nuclear material (also known as nuclear forensics) while (iii) reducing human exposure to radiation. The discovery experimentation process and the manual process, which serve as the baseline, are described in more detail below.

\subsection{Discovery Experimentation Process}

The Summer Institute discovery experimentation process is shown in Figure 1. The ultimate goal is to innovate new complete mission capabilities; this means not just verifying that a technology works but that the system fits the missions needed by the end users and their operational, ergonomic, and training constraints. The process has three phases: screening an innovation(s) to determine if it has sufficient technical maturity and fits the requirements of the desired missions, conducting the discovery experiment itself with sufficient physical and concept-of-operations fidelity to test propositions using data collected in the field, and analyzing the data to determine how the technology can be refined to meet a suitable mission as well as identify any hardware or software technology gaps, any systems gaps leading to barriers in the data-to-decision (D2D) process, or cognitive barriers using cognitive work analysis (CWA). The result of the analysis phase is a determination of whether some technologies are not suitable for radiological response and thus manufacturers should not invest in pursuing a nonexistent market; identifying 

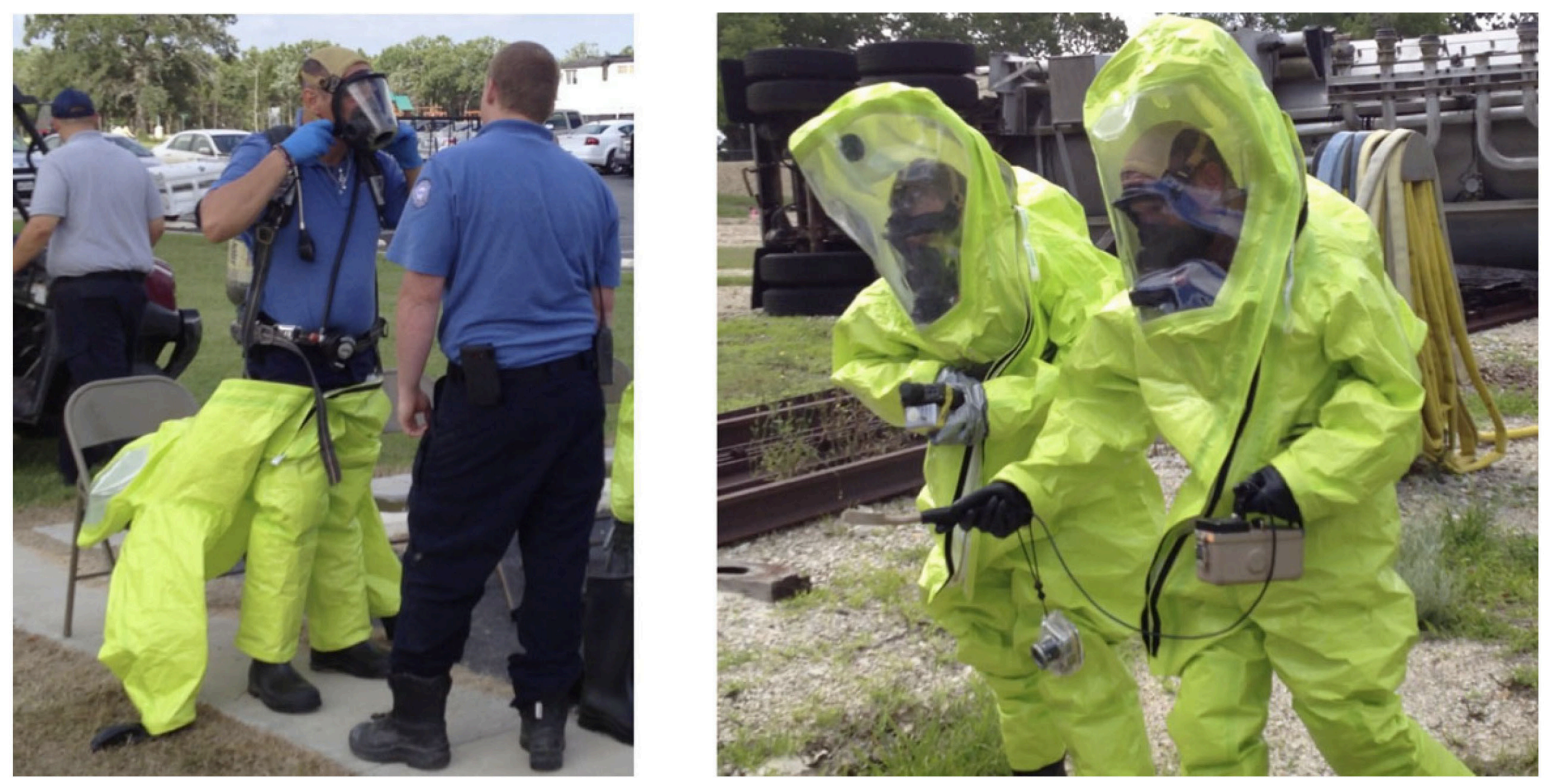

Figure 2. A responder with his respirator on and partially outfitted in a Level A suit (left), and two responders carrying a camera, radiation sensor, and four gas sensors to enter a hot zone (right).

if a technology is sufficiently mature and capable that it could be immediately adopted with minor upgrades, use doctrines, and training for early adopters; detecting system performance barriers and generating new methods or metrics to better capture these in the field; and uncovering new research questions.

The discovery experimentation process for 2013 started in December 2012 when subject matter experts from the Texas A\&M Engineering Extension Service (TEEX) identified a radiological response mission capability to be of interest. The SMEs provided a basic scenario and a list of technology requirements. Using that scenario and list, the Center for Emergency Informatics (CEI) and the General Dynamics EDGER _ industry consortium circulated calls for participation for unmanned systems, sensors, and D2D and situation awareness software.

The screening phase began in March of 2013, when the SMEs reviewed the candidate technologies and selected a subset based on how well the technologiesmatched the mission requirements (e.g., needed verification) or offered an interesting capability (e.g., needed exploration). The SMEs selected three SUASs, though only two could participate, as well as several ground vehicles, sensors, wireless repeaters, and software packages. Note that discovery experimentation is not an inclusive event because not all technologies are sufficiently mature to participate in a high-fidelity situation, the interest by the responders does not apply equally to all innovations, and because the data collection process must be tailored to the devices or packages. Of the three invited SUASs, two committed to participation, as participants were required to cover their own costs.
The experimental phase began at the same time as the requests for participation and invitations were being extended. The CEI team created a set of propositions to guide the construction of a data collection plan that would capture both the physical performance and the general cognitive system performance and bottlenecks. Technologies with data logging capabilities were integrated into the RESPOND-R test instrument whenever possible for centralized data collection. The RESPOND-R test instrument is a logging platform for robotic and cyber-physical systems used in emergency response (Shrewsbury,Henkel, Kim, and Murphy, 2013). It acquires sensor data from agents in the field and relays real-time information to listening parties for logging and analysis. RESPOND-R data management includes archival data propagation, classification, and visualizations. The RESPOND-R framework was developed on top of the Robot Operating System (ROS) and is currently integrated with the iRobot Packbot 510, AirRobot 100B, and the AEOS Marcy as well as stand-alone sensors, including the Davis Vantage Vue weather station, Canberra Radiac Geiger Counter, and RAE Systems PPBRAE.

The analysis step of the discovery experiment in Figure 1 is ongoing; this article reflects the technological gaps and the CWA of the data collected with the SUAS with respect to autonomy.

\subsection{Manual Radiological Surveys and Forensics}

Radiological surveys and forensics have traditionally been conducted by a team of six human specialists: two in Level A suits to enter the hot zone carrying radiological and gas sensors, as shown in Figure 2, two in Level A suits 
in reserve to rescue the two down range if necessary, and two to assist with donning the gear and decontamination when they return. It takes on the order of $1 \mathrm{~h}$ to set up the decontamination system, don the gear, and enter the hot zone for the assessment. Typically, the responders do not report observations in real time, so it is on the order of 45-60 min before they return with radiological readings and a verbal assessment of the situation. Furthermore, the density of sensor readings and the quality of the assessment may be hampered by the protective suits, as the plastic suits restrict mobility and visibility. As seen in Figure 2, the down range team literally has their hands full with sensors and cannot manage a camcorder, thus a SUAS with a suitable payload could provide real-time, dense sampling.

The concept of operations is that two suited responders would first approach a damaged building with a potential radiation hazard to make an initial assessment of the situation. If radiation is present, they would then follow up by localizing the radiological source. The initial assessment of the situation determines how far the scene extends, what buildings are involved, and whether there is any imminent danger, such as from radiation or gas leaks. The responders would prefer to have Google Earth or other satellite images of the incident to help plan the down range activities, but these images are at best days old and give no indication about the current scene, thus SUASs are an attractive option for obtaining actionable overhead imagery. If a radiological source was confirmed during the initial assessment, it would need to be located and mitigated in order for the rest of the response to move forward. Throughout all missions in a response, the most important rule is to be as accurate as possible because inaccurate information can cost time and resources, or worse, put lives at risk.

\section{Experiments}

The propositions for the 2013 Summer Institute were based on the gaps observed in the 2012 Summer Institute, which focused on a chemical train derailment (Duncan and Murphy, 2013), illustrating the feedback loop of "refine discovery experimentation" in Figure 1. The expectations for the use of SUASs for a radiological event were as follows:

missions would be conducted faster with SUASs than manual inspection,

1. vehicle and navigational autonomy would be challenging due to low altitude flights and proximity to urban structures,

$\checkmark$ the D2D process would experience bottlenecks, and as a result mission autonomy capabilities needed to overcome these bottlenecks would be identified.
The radiological discovery experiment had five steps. The familiarization step was held on June 4, 2013, where the SMEs had hands-on interaction with the technologies corresponding to basic awareness training; this basic level of training is consistent with how a new technology would be introduced ad hoc to the Public Safety community before more detailed and formal training occurred after purchasing the equipment. The second step, which occurred on the morning of June 6, was a table-top exercise style walk-through of a typical radiological response conducted by representatives of local, state, and federal agencies that would be responsible for responding to a radiological event to describe the response process, as it would likely be conducted by a group of researchers and industry representatives. The third step, which occurred on the afternoon of June 6, was to simulate the insertion of the technology into a response, where the technology teams had to report to the Incident Commander, be assigned to a responder team, were given a location and mission, and then were allowed to enter the warm zone, which is the area identified by the safety officers to be off limits to personnel not actively involved in the response. In addition, a trained human-machine system observer accompanied the responder team. The insertion maintained a high degree of operational fidelity, where the SUASs were being used and directed by responders as if it were a real response with safety procedures, stand-off distances, radios, and communication protocols followed. The response continued until the mission objectives were met, though in prior Summer Institutes, some events ended without meeting the objectives when it became obvious that a technology could not accomplish the goal; unlike Advanced Technology Concept Demonstrations used by the military, which try to ensure that the technology succeeds and will retry or adapt to the scenario, discovery experimentation accepts mission failure as a valuable data point. The fourth preliminary feedback step concluded with a "hot wash" or preliminary after-action report immediately following the simulated response. The fifth step was a broader, facilitated after action review (AAR) conducted on the morning of June 7. The data collection team produced a preliminary synthesis of the results from data collection, and the SMEs worked on their observations overnight.

\subsection{Staging of the Discovery Experiment}

The experiment was staged around Building 133 at TEEX's Disaster City R _ complex, which is in Class D airspace. The prop is a simulated building collapse capturing the key attributes of the Alfred P. Murrah Federal Building, which was destroyed in the Oklahoma City Bombing. It is a three-story concrete building with rooms filled with office furniture, an attached parking garage collapsed onto cars, and a dense rubble pile on one side. The prop provides the same materials, construction style, and furnishings that multistory commercial buildings 

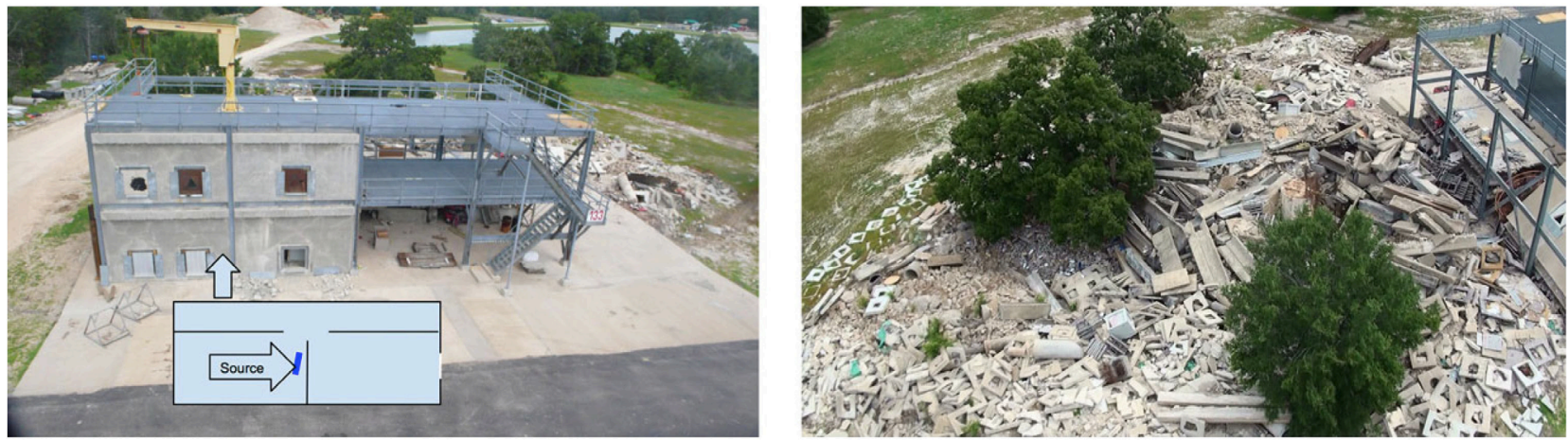

Figure 3. Building 133 (left) at Disaster City ${ }^{\circledR}$ with the location of the radiological source on the first floor toward the rear of the building. Rubble pile behind building (right).

would contain and that would absorb radiation. A "hot" radiological source, Cesium-137, emitting at 10 times the level of background radiation levels was placed in an interior room on the first floor (see Figure 3).

Two platforms were used, namely an AirRobot 100B owned and operated by the Center for Robot-Assisted Search and Rescue, and a Leptron Avenger owned and operated by Leptron.

(1) The AirRobot 100B (AirRobot, 2007), shown in Figure 4, is a quadrotor commonly used by the U.S. Army, and it is representative of the typical interfaces and data acquisition capabilities of small multi-rotor UASs. It has a single wire ring that protects the rotors from damage in a light collision. The AirRobot carried only a video or thermal imaging payload. TheAirRobot has autonomous waypoint navigation and return-toposition behaviors, but these were not used because the mission specialists wanted to see and direct in real time.AGammaPix radiation detector on a cell phone was considered as a payload, but the sensitivity of the sensor was too low to be of value and thus it was not used in this study.
The Center for Robot-Assisted Search and Rescue has now developed a radiological payload for this vehicle which holds both a camera and a Personal Radiation Detector and will test this payload at theWinter Institute in November 2013.

( The Leptron Avenger (Leptron, 2013), shown in Figure 4 , is a single-rotor system based on a TREX frame commonly used by law enforcement, and it features the capabilities of a larger system with heavier payload capabilities. The Avenger had the ability to either be flown by the pilot's hand controller or to plot flights via a ground control laptop to specify both a path and specific points of interest at a given altitude. It was modified to carry a Thermo Scientific RadEye PRDER High-Sensitivity Personal Radiation Detector (Scientific, 2013) supplied by the CST and taped to its airframe upside down to get a better reading. Due to the fact that the RadEye did not have a logging function, the onboard camera was used to monitor the readings, which required the pilot to fly heads up and sacrificed any visual data about the incident when monitoring the sensor.
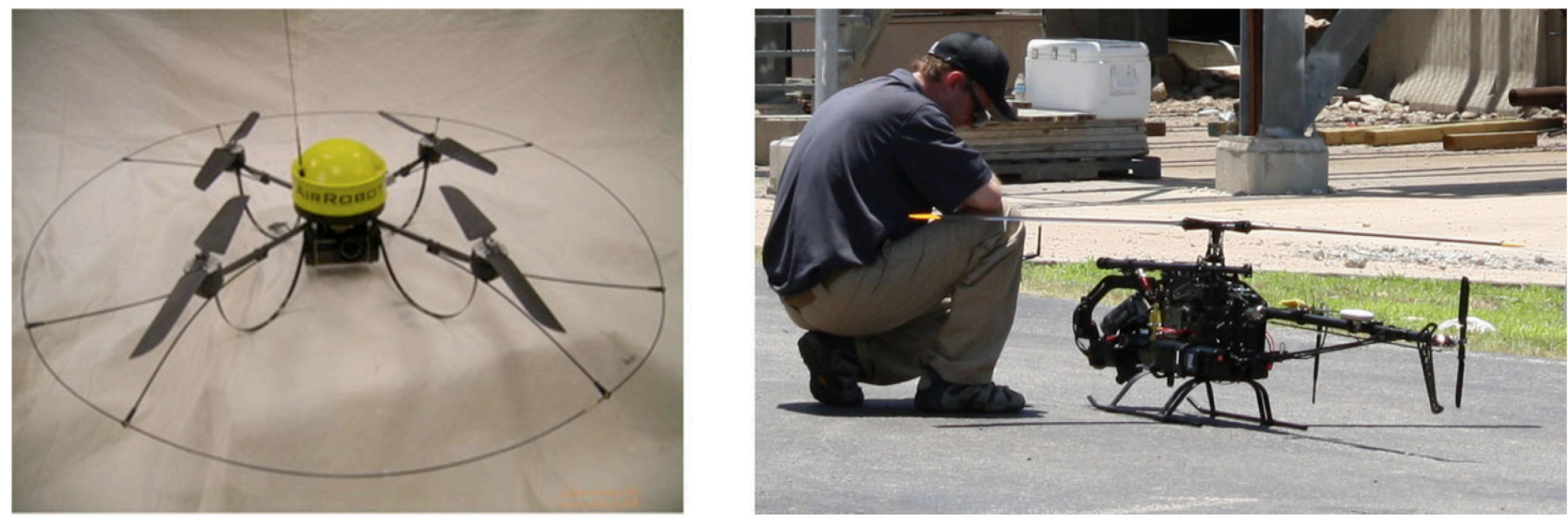

Figure 4. AirRobot 100B (left) and Leptron Avenger (right). 
Table 1. Mean (SE) of $X$ and $Y$ search locations for each group for the five test conditions in experiment 1

\begin{tabular}{|c|c|c|c|c|c|c|c|c|c|c|}
\hline \multirow[b]{2}{*}{ Group } & \multicolumn{2}{|c|}{ Control } & \multicolumn{2}{|c|}{$\mathrm{C}+10 \mathrm{~cm} \mathrm{X}$} & \multicolumn{2}{|c|}{$\mathrm{C}+10 \mathrm{~cm} \mathrm{Y}$} & \multicolumn{2}{|c|}{$\mathrm{E}+10 \mathrm{~cm} \mathrm{X}$} & \multicolumn{2}{|c|}{$\mathrm{E}-10 \mathrm{~cm} \mathrm{Y}$} \\
\hline & $x$ & $Y$ & $x$ & $Y$ & $x$ & $Y$ & $x$ & $Y$ & $x$ & $Y$ \\
\hline 1 & $\begin{array}{l}-2.21 \\
(1.53)\end{array}$ & $\begin{array}{c}0.50 \\
(1.51)\end{array}$ & $\begin{array}{c}8.00 \\
(1.71)\end{array}$ & $\begin{array}{l}-0.02 \\
(1.13)\end{array}$ & $\begin{array}{l}-1.84 \\
(1.64)\end{array}$ & $\begin{array}{c}2.54 \\
(1.40)\end{array}$ & $\begin{array}{c}0.31 \\
(2.01)\end{array}$ & $\begin{array}{c}0.42 \\
(1.00)\end{array}$ & $\begin{array}{l}-3.92 \\
(2.08)\end{array}$ & $\begin{array}{l}-4.56 \\
(1.18)\end{array}$ \\
\hline 2 & $\begin{array}{c}1.69 \\
(2.40)\end{array}$ & $\begin{array}{l}-0.06 \\
(1.37)\end{array}$ & $\begin{array}{c}8.86 \\
(1.94)\end{array}$ & $\begin{array}{l}-0.19 \\
(1.22)\end{array}$ & $\begin{array}{c}2.44 \\
(2.03)\end{array}$ & $\begin{array}{c}4.75 \\
(1.28)\end{array}$ & $\begin{array}{c}3.09 \\
(2.63)\end{array}$ & $\begin{array}{l}-0.25 \\
(0.85)\end{array}$ & $\begin{array}{l}-1.56 \\
(0.65)\end{array}$ & $\begin{array}{l}-2.73 \\
(1.23)\end{array}$ \\
\hline 3 & $\begin{array}{l}-1.79 \\
(3.77)\end{array}$ & $\begin{array}{l}-0.11 \\
(3.49)\end{array}$ & $\begin{array}{c}5.31 \\
(5.77)\end{array}$ & $\begin{array}{c}2.58 \\
(5.21)\end{array}$ & $\begin{array}{l}-4.36 \\
(1.72)\end{array}$ & $\begin{array}{c}2.08 \\
(1.71)\end{array}$ & $\begin{array}{l}-0.32 \\
(4.29)\end{array}$ & $\begin{array}{c}2.44 \\
(2.44)\end{array}$ & $\begin{array}{l}-1.10 \\
(5.00)\end{array}$ & $\begin{array}{c}0.96 \\
(2.23)\end{array}$ \\
\hline
\end{tabular}

C: Cylinder; E: edge. Each search location is defined in centimeters away from the training position of the goal.

TheSMEs participating in the experiment were hazardous material specialists from TX-TF1 and the Texas National Guard's CST, both of which would be expected to send personnel to directly approach, localize, and mitigate the radiological incident, and TCEQ, which would respond to and assist in mitigation and recovery from a radiological event.

\subsection{Missions}

The team was assigned two missions by the incident commander: first an initial assessment followed by a request for radiological source localization. The SUASs were able to survey the incident and localize the source in two flights. Since there were two SUASs, each flew the same mission, for a total of four flights, though as will be discussed in Section 5, the difference in platforms led to different strategies. Table I summarizes the flights. All flights were conducted in line of sight and teleoperated. The SUASs did not fly through radioactive dust or materials, so the they did not have to be decontaminated. Since the team worked from the warm zone and did not handle a contaminated robot, they did not have to wear protective gear.

The UAV team was made up of three members following the concept of operations established in Pratt, Murphy, Stover, and Griffin (2009) and used for responses in Italy (Kruijff et al., 2012) and Cyprus (Angermann, Frassl, and Lichtenstern, 2012): a Pilot, a Safety Observer, and a Mission Specialist. The Pilot-in-Command of all flights was a licensed private pilot, as required by the FAA, but the primary Pilot for a given platform was determined by the amount of time accumulated flying that robot. The mission specialist, who was the responder in charge of the mission, directed the pilot and communicated with the Incident Command staff via a radio. On AirRobot flight one and Avenger flight two, two responders acted as mission specialists, though in a real deployment there most likely would have been oneMission Specialist to keep the team size as small as possible. The mission specialists rotated out with one from TCEQ, primary on Avenger flight two, and one from CST, primary on both AirRobot flights and Avenger flight one. The safety officer was a CRASAR SUAS specialist, either Tanner Perkins or Robin Murphy, trained for the position and concerned with airspace and responders or ground robots working beneath the SUAS, vehicle safety, and team safety. The Pilot was Brittany Duncan for the AirRobot and Scott Heath was the Avenger Pilot.

Data from the SUAS were collected and archived using the RESPOND-R test instrument. The data from each SUAS were robot-eye video recorded by the SUAS, flight data recorded by the SUAS, and time stamps of the data. In addition, the flight logs filled in by the SUAS team, observational logs of the SUAS team activities, and observational logs of the incident command activities were collected.

\subsubsection{Mission 1: Initial Assessment}

The SUAS team was tasked to leave the Base of Operations and enter the "warm zone, "maintaining a standoff distance of $125 \mathrm{~m}(410 \mathrm{ft})$ from the source. Staging Area 1 corresponded to the same standoff distance for a manual team. For a map of the warm and hot zones, refer to Figure 5. Due to line-of-sight limitations on the SUAVs, the team chose to set up at the intersection of two roads just outside of the warm zone. The team was approximately $500 \mathrm{~m}$ from the Base of Operations without reliable wireless connectivity either through a local MANET or cellular service. The time from arriving at Staging Area 1 to the first SUAS in the air was 16 min.

The AirRobot flew the first flight, and completed a visual inspection of the building by flying to the middle of the incident and completing two 360 degree rotations while getting complete coverage with a 10 megapixel still camera, then flying around to get pictures of all sides of the building.

The Avenger flew the second flight and completed a visual inspection by flying around the exterior of the incident switching between FLIR and high-resolution video, then it conducted a radiological survey with the RadEye sensor to confirm the presence of a radiological source. The mission specialist directed the flight and reported higher radiological readings to incident command after landing.

After each flight, the mission specialist(s) prioritized 


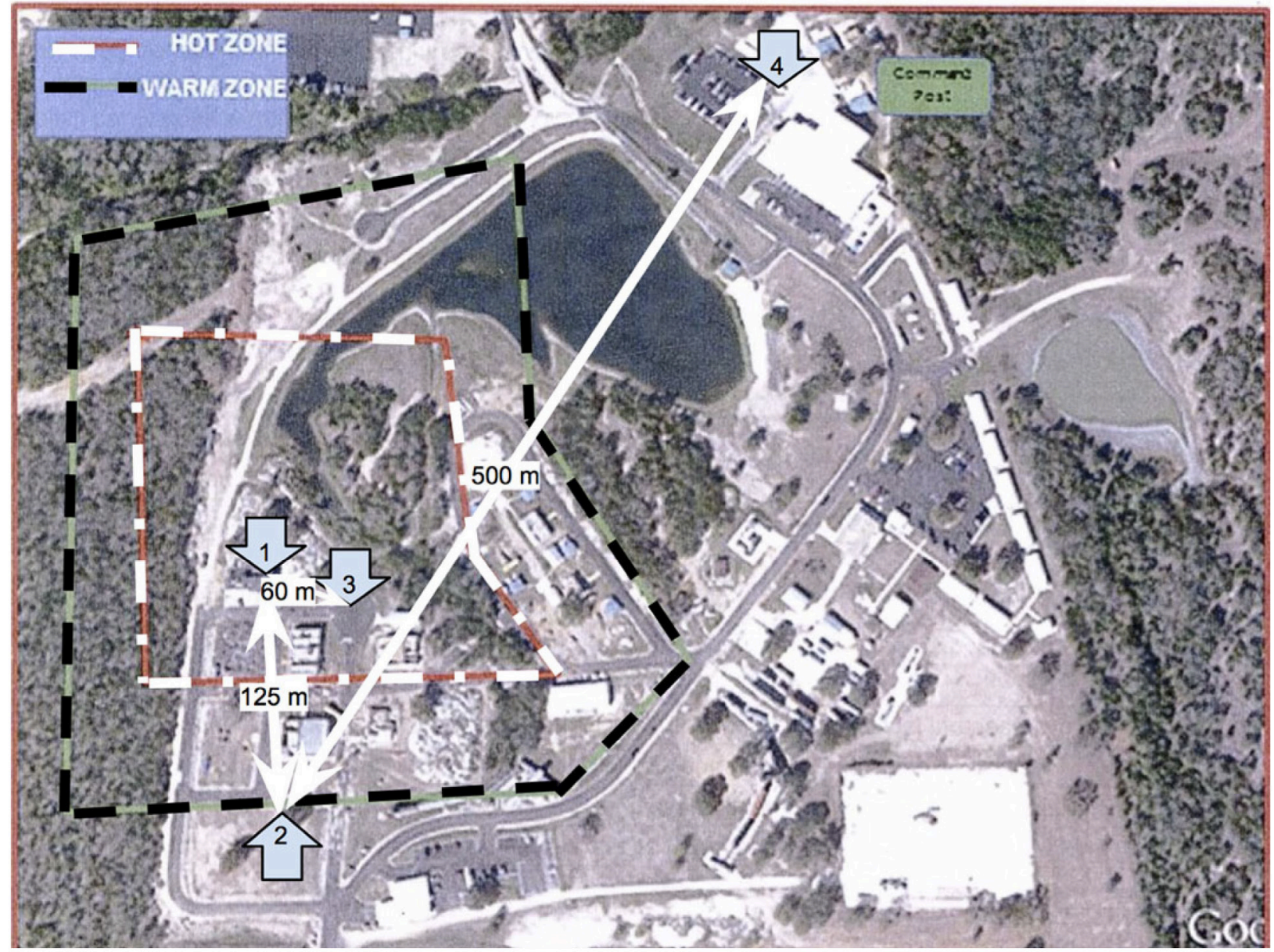

Figure 5. A map showing the "warm zone" and "hot zone" distances in the Summer Institute Exercise in reference to the "hospital collapse" (1), first staging area (2), second staging area (3), and Incident Command (4).

the still pictures and videos from the flights to be sent to incident command so that it could be triaged when it arrived. Data for the incident commander were sent via thumb drive by having a data manager walk or drive it to the command post. The thumb drive with the photos from flight 1 was available $14 \mathrm{~min}$ after landing and took an additional $8 \mathrm{~min}$ to transport to command, so it was delivered $22 \mathrm{~min}$ after landing. Video from flight 1 was sent with the video and picture data from flight 2 . This thumb drive was available $4 \mathrm{~min}$ after landing and arrived at command 5 min later, so it was delivered 9 min after landing.

The outcomes of the first mission were as follows:

1) the extent of the physical damage was captured visually, and

2) the radiation was determined to be less than expected and thus the warm zone boundaries were decreased.

\subsection{Mission 2: Radiation Source Localization}

After completing Mission 1, the SUAS team was directed to conduct a radiation source localization mission, but were allowed to move closer to the incident and launch from Staging Area 2.

The Avenger flew the third flight while providing real-time data from the RadEye sensor in order to locate the source and confirm on what floor of the building it was located. The mission specialist guided the flight and used the secondary mission specialist to call the highest readings to incident command during the flight. After the flight, the highest reading was confirmed with incident command, along with its approximate location on the front of the building. The mission specialist essentially used a "greedy search" by following the increasing readings and avoiding the decreasing readings to direct the pilot to fly to the highest readings.

The AirRobot flew the fourth flight to simulate a radiological source localization with a closer proximity to the building and the ability to scan the front of the building in a more organized fashion due to the hoop protecting the blades. After this scan was complete, the AirRobot was tasked to complete a more thorough visual inspection to try to locate a picture of the source if possible. 
The outcome of the second mission was a determination that the source was on the first floor, but no visual of the source was captured. As in Mission 1, still photos and videos were recorded to a thumb drive and delivered by the data manager to the incident commander. The data from flight 3 were available $24 \mathrm{~min}$ after the flight and took 9 min to walk to command, so they were delivered $33 \mathrm{~min}$ after landing. Flight 4 sent the data $5 \mathrm{~min}$ after landing, and they arrived $6 \mathrm{~min}$ later for a total of $11 \mathrm{~min}$ after landing.

\section{Cognitive Work Analysis}

A CWA (Vicente, 1999) was conducted on the data gathered by the discovery experiment in order to establish the preliminary domain theory and to determine if the propositions in Section 4 were supported. CWA is a tool for understanding a formative domain, one where an innovation has the potential to change or eliminate existing tasks. It was used to create SUAS crew organization and protocols from flights after Hurricane Katrina in 2005 (Pratt et al., 2009); the resulting concept of operations was used at the 2011 Fukushima nuclear accident, the 2011 Cyprus explosion (Angermann et al., 2012), and the 2012 Finale Emilia earthquake (Kruijff et al., 2012). CWA consists of five components: a work domain analysis, which models what SUASs are expected to do and the conditions or constraints under which they operate, control task analysis and strategies analysis, which identify the specific, reoccurring tasks in the domain that must be done (control tasks) and how they are done (strategies), and social organization and cooperation analysis and worker competencies analysis, which capture the sociotechnical factors that can influence the acceptability of autonomy. Of these, the control task and strategies analyses are the most critical for identifying specific autonomous capabilities because they represent specific desirable capabilities that are candidates for autonomy.

\subsection{Work Domain}

The discovery experiment suggests that the work domain will benefit from the introduction of SUASs overall as SUASs will reduce the number of responders and accelerate data gathering. The overall missions, work flow, and location of the team will remain the same and the general time associated with getting the initial set of information will be decreased by $53 \%$, but though there will be imagery added to the data-to-decision process, the process itself will remain unchanged. The introduction of a SUAS raises the question of how it will be decontaminated or maintained between flights. Furthermore, the personnel protection equipment makes it impractical to manually extract a SD card from a SUAS or perform other complex manipulations such as changing batteries.
The missions, work flow, and location of personnel appear to be the same. Both a manual and a SUAS team would conduct the same two missions: initial assessment and radiation source localization. Note that the perimeter detection mission proposed in the research literature (Clark and Fierro, 2005) appears to be a task within the initial assessment mission, not a distinctly separate mission. There is a possibility that a SUAS could conduct both missions in one flight, though the results of the initial assessment may allow the team to move the helispot closer for a more conducive line of sight for performing the localization mission. Both types of teams would have access to the same types of information prior to the missions (e.g., Google Earth maps) and the same reporting requirements. The entry/collection point at the warm zone for both teams would be on the order of 125-300 $\mathrm{m}$ from the presumed area of interest for a small incident, though for the Fukushima nuclear incident the helispot was within the hot zone and on the order of $1-1.6 \mathrm{~km}$ from the reactor buildings.

ASUAS could reduce the number of responders needed for a mission from six to three and, under ideal conditions, reduce the number exposed to radiation from two to zero. A manual team requires six responders: two in Level A suits to enter the hot zone, two in Level A suits in reserve to rescue the two downrange if necessary, and two to assist with donning the gear and decontamination on return. A SUAS eliminates the need for the two downrange and the two in reserve, assuming that the SUAS does not need to be retrieved and decontaminated by a suited responder. As described in Section 4, a SUAS team consists of three members.

A SUAS can accelerate the acquisition of actionable data and possibly provide higher-quality data. The first flight of a SUAS during the experiment occurred $16 \mathrm{~min}$ after the team arrived at the helispot, with the mission specialist beginning to make radio observations to the Incident Commander at $50 \mathrm{~min}$ after arrival, $2 \mathrm{~min}$ after the second flight landed, to let command know that radiation levels were elevated over the southern part of the collapse. A manual team would take on the order of $1 \mathrm{~h}$ to set up the decontamination system, don the gear, and enter the hot zone (see Figure 2). Typically, the responders do not report observations in real time, so it is on the order of $45-60 \mathrm{~min}$ before they return with radiological readings and a verbal assessment of the situation. However, the density of sensor readings and the quality of the assessment may be hampered by the protective suits, as the plastic suits restrict mobility and visibility. As seen in Figure 2, the downrange team literally has their hands full with sensors and cannot manage a camcorder. The recorded imagery from a SUAS may be of greater overall utility.

While a SUAS can in theory provide significant benefits to a radiological response, current SUASs may have to be redesigned in order to be adopted. The major 


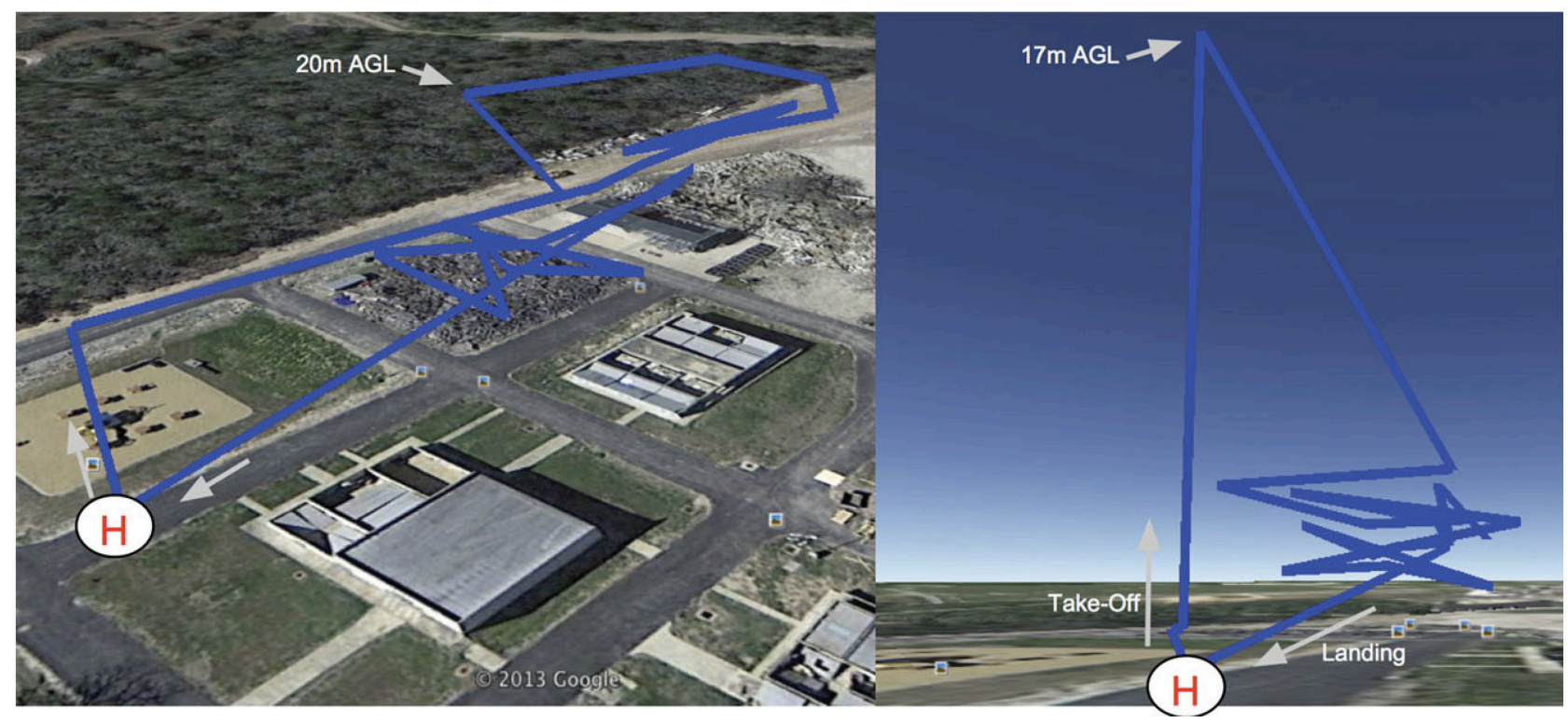

Figure 6. Avenger Flight 1 conducting initial assessment, then radiological source localization. Flight path coverage is on the left, and a view of the altitude profile for the flight path is on the right.

issue is decontamination of the SUAS. If the SUAS cannot be decontaminated, it can remain in the hot zone but will require a responder in personal protective equipment (PPE) to enter, recharge it, replace any recording media, etc. The responder must then be decontaminated, etc., increasing the manpower needs and logistics tail. The ergonomics of manipulating a SUAS in PPE may influence the system design. A secondary issue for SUAS adoption is possible susceptibility to radiation, however this was not seen at Fukushima.

\subsection{Control Task and Strategies Analysis}

The initial assessment is generally accomplished by getting as much information as possible from both a visual scan and a limited amount of sensor data, such as radiological and gas readings. If possible, these would be conducted at the same time, and data from all sensors would be recorded. As a side effect of the radiological survey, the perimeter detection task should be completed and may allow for a reduction in the hot zone and warm zone areas. After the mission, it would be preferable to be able to cue up a full playback of the mission, including the telemetry, video, and sensor data at any given point in the flight. Additionally, GPS tagging on all data (images, sensor readings) is necessary for them to be valuable to the overall operations at incident command.

\subsubsection{Initial Assessment Mission}

The initial assessment mission is characterized as generally providing comprehensive visual coverage from a low altitude, $22-40 \mathrm{~m}$. The altitude appears to be a function of the desired view, where higher gives a wider view, and the height of the structures. However, these altitudes appear too high for a useful radiological survey and just indicate the presence of radiation. The two strategies were a formal strategy for ensuring coverage of the visual imagery and an ad hoc clockwise sweep.

The strategy used by the AirRobot for the mission (Air- Robot Flight 1) had two steps. First, the pilot flew the SUAS to what appeared to be the middle of the incident area and took 17 pictures in a 360 degree pattern (eight pictures each at 60 and 30 degree camera tilt angles and one looking straight down) in order to get overlapping images that provided full coverage of the rubble pile and the building. The collection of images would be suitable for tiling into a master image or for a reconstruction program such as photosynth. While an automated process for this exists on the AirRobot platform, it was not used at this time in order to allow the mission specialist to pause the process if a point of interest was identified. The pilot then continued around the building to get pictures of all four sides, similar to elevation views. The flight path is not shown.

The strategy used by the Avenger for the mission was for the pilot to fly a clockwise sweep around the area of interest; this was approximately the first $3 \mathrm{~min}$ of Avenger Flight 1. The flight path for the entire flight is shown in Figure 6.

\subsubsection{Radiation Localization Mission}

The radiation localization mission is characterized by extremely low altitude flights $(0.3 \mathrm{~m})$ in close proximity to structures $(1.5 \mathrm{~m})$ and terrain $(1.5 \mathrm{~m})$. The actual strategies used for the Avenger and AirRobot were different due to the differences in their design. The Avenger used a greedy search around the front face 

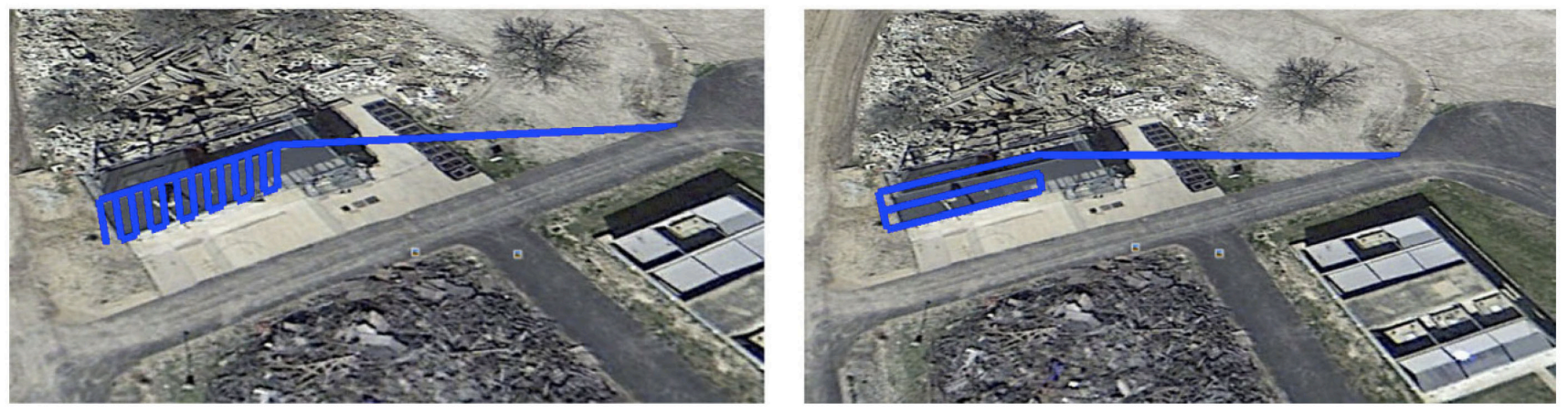

Figure 7. Requested vertical raster scan (left) and proposed horizontal raster scan (right).

of the building with a standoff distance of $3 \mathrm{~m}$, while the AirRobot used a horizontal raster scan from top to bottom with a standoff distance of $1.5 \mathrm{~m}$. In the AirRobot flight, the mission specialist intervened to direct the robot to opportunistically gather information. While the mission specialist did not offer a strategy for the initial assessment mission, there appeared to be strong opinions on how to accomplish the radiation localization mission. For a multistory building, either a horizontal or vertical raster scan of each face of the structure (see Figure 7) is desired by the SMEs to provide repeatability and complete radiological coverage. However, the SME did not give quantitative sensing requirements, and it is possible that any strategy that provided a sufficient survey would be acceptable. Additionally, a request was made for either of the SUAS platforms to complete a scan over the rubble pile at $1.5 \mathrm{~m}$ to verify that there was not another source in the rubble. Due to the low altitude requested and the variability of the pile, both pilots and safety officers declined.

The Avenger conducted a radiation localization mission as the later portion of its Flight 1 and then as a dedicated Flight 2. For the later portion of Flight 1, the strategy was a raster scan at a constant altitude. The pilot directed the Avenger in a raster scan over the two-story building at a constant altitude of $16 \mathrm{~m}$ while avoiding the gantry (see Figure 8). The flight path for Avenger Flight 1 shown in Figure 6 suggests that the raster scan was not uniform, but transitioned into a lower altitude scan $(6 \mathrm{~m})$ in front of the building after an initial high sensor reading.

The Avenger on Flight 2 used a greedy search, with the flight path shown in Figure 9. It was reconfigured to direct its video camera to the display for the radiological sensor, forcing the pilot to fly heads up but allowing the mission specialist to see the radiation readings in real time. The ability to fly heads up was possible because the team had moved to StagingArea 2 when the warm zone was reduced. As the Avenger flew in a horizontal scan from the top of the building to almost landing (0.3 $\mathrm{m}$ minimum altitude), the mission specialist called out radiation readings and the pilot began to fly to maximize

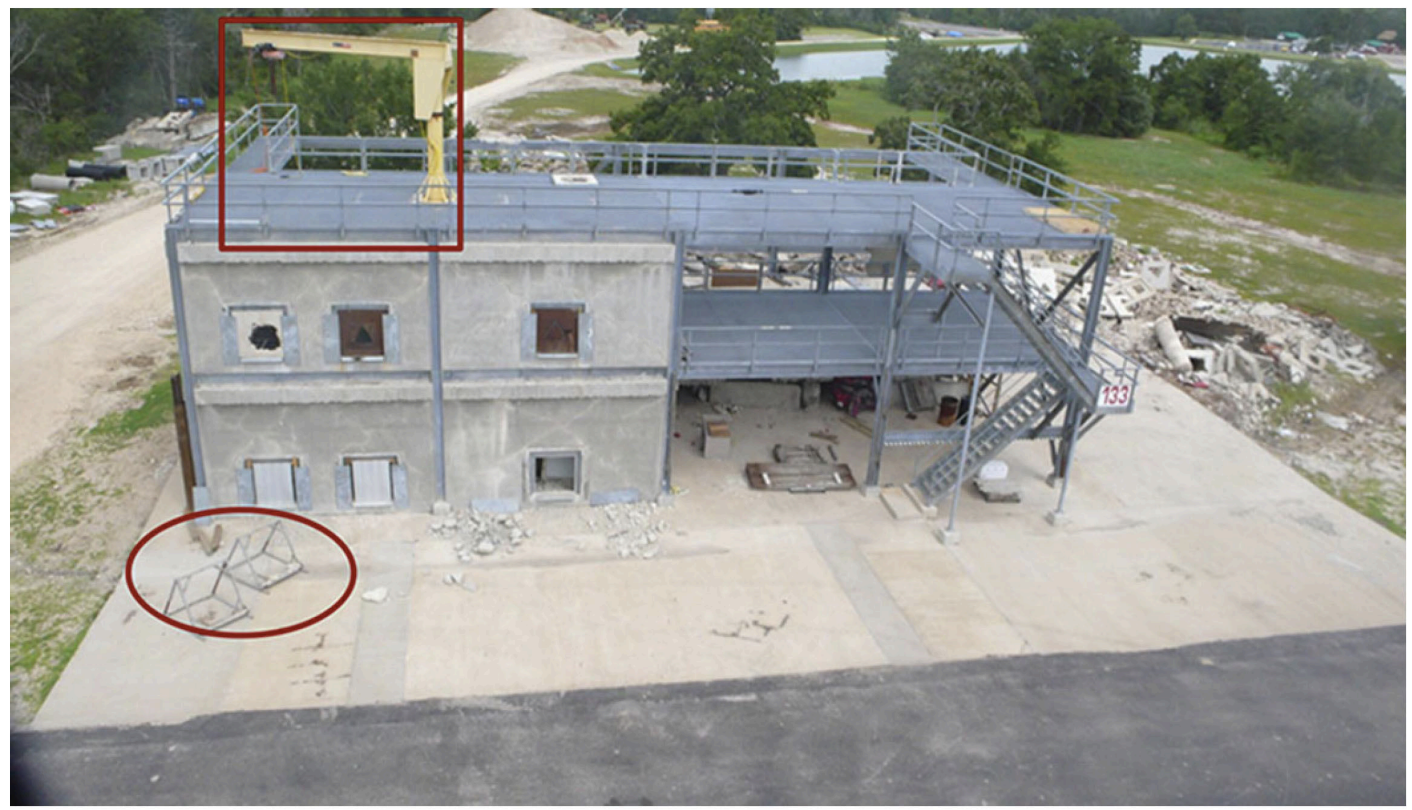

Figure 8. Obstacles that may interfere with flights, but may not be shown on a map. 


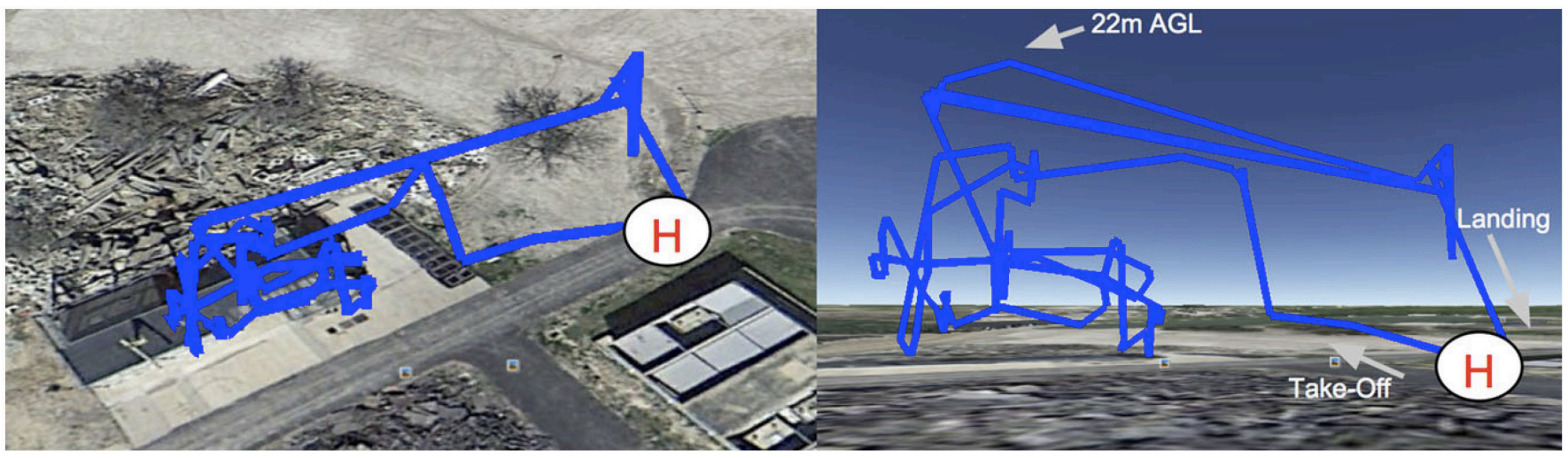

Figure 9. Greedy scan for source localization by the Leptron Avenger.

the value. The Avenger attempted to stay around $3 \mathrm{~m}$ off the structure, balancing wind gusts, GPS shadows, and the possibility of a collision with the sensitivity of the sensors to radiation based on distance. The greedy search algorithm was hampered by the inability of either the pilot or the mission specialist to remember where the highest readings were taken. This increased the cognitive workload of the pilot and the mission specialist. The pilot had to attempt to associate readings with locations while flying, while the mission specialist had to look up to see the location of the robot, then back down to the sensor display.

The AirRobot conducted a simulated radiation localization mission on Flight 2, shown in Figure 10, as it did not have a radiological payload. For this flight, the AirRobot attempted a horizontal scan over the front of the building with instructions to get "as close as possible," which translated in practice to a $1.5 \mathrm{~m}$ standoff distance. The AirRobot was able to operate closer to the structure because of the wire safety hoop. During the course of the flight, the mission specialist interrupted the raster scan to take pictures through the windows to see if any other visual information could be gained. After the conclusion of the pattern to the satisfaction of the SMEs, it was requested that the AirRobot fly close to the top of the building to see if it was possible to spot the source through the grates of the building's ceiling, and finally to see if the source could be seen by looking in the doorway on the side of the building closest to the pilot.

\subsection{Social Organization and Cooperation Analysis and Workers Competencies}

The social organization and cooperation analysis and the assessment of workers competencies provide insight into the expectations for autonomous capabilities and how autonomy might best complement the responders' skills and interests. The control tasks and strategies analyses suggest a high degree of vehicle and navigation autonomy, while the user-oriented analysis (i) confirms the need for autonomy to complement the demanding flight regimes (e.g., vehicle and navigational autonomy) and (ii) suggests that autonomous data processing (e.g., mission autonomy) is a valuable capability.

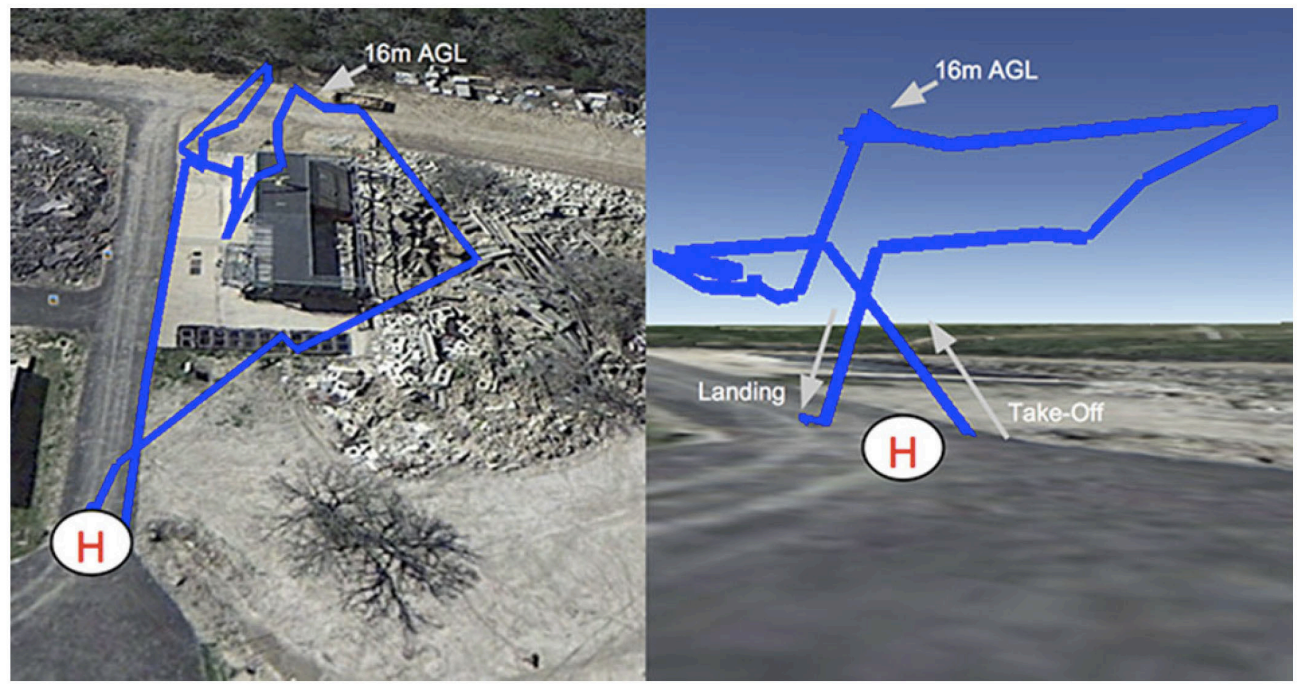

Figure 10. A path of the AirRobot's flight around the hospital building. 
The social organization and cooperation analysis showed, not surprisingly, a hierarchical command and data to decision process, where the SUAS team provides their superior with relevant data. For both robots, the data digestion process consisted of copying imagery and geotagged stills to a USB drive. There was no indication that a USB drive with 2.2 GB of data was viewed, as the incident command staff would have had to sort through the files. Data digestion in the field by the SUAS team can be difficult. The radiation data were not georeferenced, and, as with Fukushima, would have had to be manually aligned with the GPS location of the platform for the time stamp of the radiation data. The SMEs wanted the radiation readings placed on an image of the incident as the most useful visualization. To provide this level of data digestion manually, the SUAS team would have to be expanded to add another member or one of the team members would need to acquire a new role.

The SMEs treated the missions as remote presence tasks, not taskable agent tasks (Murphy and Burke, 2008); they expected to direct the robot and essentially use it as an extension of themselves into the remote area of interest. This suggests that shared control between the pilot and mission specialist ("ok, you point it where you want to look"), with the robot providing guarded motion, may be of value. It is unlikely that for the foreseeable future the responders will have team members who can be diverted for training as a pilot, especially formissions that require low altitude, close proximity flights. This places greater demands on reliable autonomous capabilities to reduce the training load and to reduce any chance of failure, as the robot will likely crash.

\section{Implications for Autonomy}

The discovery experimentation provides both a preliminary domain theory for the use of a SUAS for radiological response and, by extension, for near earth, low altitude, close proximity flights in terms of vehicle, navigational, and mission autonomy.

\subsection{Domain Theory for Radiological Events}

The discovery experiment indicates that a radiological event will place severe demands on guidance and control. To locate a radiation source, whose strength decreases as the square of the distance, SUASs will have to fly within $1.5 \mathrm{~m}$ of the ground surface (altitude) and structures (proximity). The terrains and structures may have been damaged in an earthquake or collapses, modified, or have cranes, scaffolding, vegetation, banners, power lines, or other unmodeled obstacles. The urban structures may interfere with GPS, as the AirRobot often dropped from 12 to 7 satellites and reported higher altitude than videotapes indicated it was flying. The experiment also provided insight into the types of obstacles, such as construction equipment and debris as well as trees and vegetation, and the terrain, such as irregular rubble varying $3 \mathrm{~m}$ in height. SUASs can reduce responder exposure, acquire data more quickly for initial assessment, and provide a more comprehensive and complete radiological survey. The types of flight paths needed are primarily for assessment and surveying the damage, which lend themselves to autonomy, but responders will need to opportunistically direct the robot to inspect conditions.

\subsection{Vehicle Autonomy}

Vehicle autonomy will have to include low cost exteroceptive sensing such as optical flow or radar to provide position-hold flight control, rather than relying on GPS and barometric pressure. While most SUASs now have joy-stick neutral flight control, it is not clear how reliable an implementation will be when the robot is expected to be $1.5 \mathrm{~m}$ in altitude and $1.5 \mathrm{~m}$ from an urban structure. The loss of GPS position information is a strong possibility, with the SUAS operating within the error range of GPS and barometers, making them particularly susceptible to wind gusts near buildings.

\subsection{Navigational Autonomy}

Navigational autonomy in SUASs have focused on waypoint navigation where the pilot enters GPS waypoints or taps locations on a map. The discovery experiment suggests that five other autonomous capabilities will be more valuable for a radiological response operating with $1.5 \mathrm{~m}$ of structures and at altitudes between 0.3 and $30 \mathrm{~m}$ : scan, obstacle avoidance, contour following, environment-aware return to home, and return to highest reading. Two of these, obstacle avoidance and environment-aware return to home, should be valuable for any near earth, low altitude application.

Scan. The two SUASs had waypoint navigation that was well suited for flying above the tree line or above structures, but waypoint navigation was not helpful for initial assessment, which is based around the team seeing the area of interest and then applying a scan algorithm to provide visual coverage, which could be autonomous. Scan algorithms are important to ensure full coverage and to limit the amount of interruption to a task that needs to be completed (e.g., tasking the pilot to look at structural issues when a radiological scan is needed). During this exercise, the control tasks and strategies analysis identified four scan algorithms: a 360 epicenter of the area of interest, a horizontal (constant altitude) raster at $32 \mathrm{~m}$ above the incident, a horizontal raster along the face of a building, and a greedy search where the goal was to gain the highest radiation reading; this leads to a recommendation that SUASs be sold with multiple full-coverage algorithms to choose from based on the incident type and weather conditions.

Obstacle avoidance. The operational envelope for the 
SUAS will be from a 1.5 to $3 \mathrm{~m}$ horizontal distance, and it will need both the ability for guarded motion if being controlled manually, or full autonomy if completing a scan. This autonomy will enable faster and more accurate scans, but it will need to be resilient to holes in buildings or rubble and other unmodeled obstacles, such as those shown in Figure 8.

Contour following. Contour following of complex rubble at an altitude of $1.5 \mathrm{~m}$ in order to detect radiation buried in a collapsed structure was repeatedly requested, but not performed due to the high risk of an accident. Contour following is distinct from scan, which has at least one plane (horizontal or vertical) that is free of obstacles. In addition to the irregularity of the terrain, the platform should also be able to update its own altitude even if it was launched from a point of higher elevation than the flight area, since pilots will often set their base station uphill from the intended flight path in order to maintain a better line-of-sight at lower altitudes.

Environment-aware return to home. Both SUASs had return-to-home upon loss of signal capabilities, but these were not designed for cluttered environments. The Air- Robot procedure is to return to the highest altitude during the entire flight and then fly directly to home and autoland. However, if the robot were under the crane or an outcropping of a damaged building, it might collide.

Return to the Highest Reading. Several SUASs now offer autonomous return to a preset location and viewpoint; this capability would autonomously analyze the incoming radiological readings during a scan and then return to the location where the highest reading occurred. This would eliminate the greedy search algorithm used in Avenger Flight 2, which did not produce a uniform radiological survey nor was it guaranteed to have the global maximum radiation reading.

\subsection{Mission Autonomy}

The most desired autonomous mission capability was not mission planning (e.g., what platform to use and what flight path to take), but rather decision-aiding by providing data digestion, or autonomous report generation. The SUAS itself should create logs showing the readings throughout the flight and match them with the robot's telemetry data in order to enable the responders (or software agents) to better filter potential points of interest. Post-processing intelligence was needed to act on the digested data and identify the highest readings, and to generate geographically based synopses of key readings and imagery to help the decision makers better understand the information gathered.

\section{SUMMARY}

Radiological response is representative of applications where small unmanned systems will be required to fly at low altitudes and in close proximity to structures. A discovery experiment was conducted with two SUASs, a single rotor Leptron Avenger, and an AirRobot 100B quadrotor, at a simulated building collapse atDisaster City R _ with a "hot" radiation source in order to ascertain autonomous capabilities that would facilitate adoption by responders. Acognitive work analysis of the data collected was conducted, and it was found that all three of the propositions motivating the experiment were correct:

SUASs can conduct an initial assessment and a radiological survey faster than a manual team; the data show that the SUAS started providing useful data in $16 \mathrm{~min}$ and it reached command within $50 \mathrm{~min}$ after arrival, $10 \mathrm{~min}$ before the responders would have even been fully ready in Level A suits. In addition to being faster, SUASs can reduce or eliminate responder exposure to radiation and reduce the number of responders needed to carry out missions from six to three.

0 Vehicle and navigational autonomy will be challenging due to low altitudes and proximity to urban structures. Low altitudes $(0.3-40 \mathrm{~m})$ and close proximity to structures $(1.5 \mathrm{~m})$ are necessary to detect and localize a leaking radiation source such as might be found in a nuclear medicine ward. A rubble pile with a suspected radiation source may require contour following of $1.5 \mathrm{~m}$. These extreme altitudes and proximity are because radiation strength decreases with the square of distance, so the SUAS must get as close as possible. In the experiment, the radiation source was on the first floor of a two-story commercial building, representing a worst case for a SUAS. While GPS was not lost, GPS coverage decreased by almost half, and if the pilot had not been actively engaged in supervision of the platform, a crash could have resulted. The experiment also indicated that unmodeled obstacles not appearing on a map or satellite image can pose major problems.

( The data-to-decision (D2D) process did experience bottlenecks that mission autonomous capabilities can overcome. The manual D2D process has a responder report any significant findings over the radio after the team returns with the data and then transports the complete dataset via a courier. A SUAS fits this process without creating bottlenecks. However, its ability to record video and still imagery along with the radiological readings offers a richer raw dataset. Though these data arrive at the same time, or earlier because of the faster start, they are not in a digested form that can be readily used by the incident commander, and they were not looked at. Perhaps the major lesson from the discovery experiment is that autonomous capabilities should be designed to augment, not replace, the human pilot and mission specialist capabilities in these harsh environments while protecting the vehicle from harm and to aid 
rapid, accurate decision making. Five autonomous navigational capabilities were identified with immediate import: scan, obstacle avoidance, contour following, environment-aware return to home, and return to highest reading. Two of these, obstacle avoidance and environment-aware return to home, should be valuable for any near earth, low altitude application.

\section{ACKNOWLEDGMENTS}

This work was supported by a National Science Foundation Graduate Research Fellowship and funded in part by NSF Grants CNS-0923203 and EIA-0224401 and the Texas A\&M Engineering Experiment Station (TEES) Center for Emergency Informatics. The authors would like to thank Mike Thorlin, Pete Palmer, and the members of the EDGER _ Innovation Network industry consortium for their participation. This work would not have been possible without the participants in Summer Institute 2013, with special thanks to Mr. Clint Arnett, Chief Warren Weidler, Scott Heath and Leptron Industrial Robotic Helicoptors, ThomasMeyer and AirRobot, Brandon Shrewsbury, and Tanner Perkins. This work was conducted under FAA Certificate of Authorizations 2013-CSA-51-COA and 2012-CSA-81-COA.

\section{REFERENCES}

AirRobot (2007). Airrobot micro unmanned aerial vehicle.

Alberts, D. S., \& Hayes, R. E. (2002). Code of best practice forexperimentation. CCRP Publication Series. Department ofDefense (USA) Command and Control Research Program.

Angermann, M., Frassl, M., \& Lichtenstern, M. (2012). Mission review of aerial robotic assessment-Ammunition explosion Cyprus 2011. In IEEE International Symposium on Safety, Security and Rescue Robotics (pp. 1-6).

Bashyal, S., \& Venayagamoorthy, G. K. (2008). Human swarm interaction for radiation source search and localization. In Swarm Intelligence Symposium, 2008. SIS 2008 (pp. 1-8), IEEE.

Clark, J., \& Fierro, R. (2005). Cooperative hybrid control of robotic sensors for perimeter detection and tracking. In Proceedings of the 2005 American Control Conference (vol. 5, pp. 3500-3505).

Duckworth, D., Shrewsbury, B., \& Murphy, R. R. (2013). Run the robot backward: Lessons learned in nuclear forensics. In IEEE International Symposium on Safety, Security and Rescue Robotics.

Duncan, B.,\&Murphy, R. R. (2013). Field study identifying barriers and delays in data-to-decision with small unmanned aerial systems. In International Conference on Technologies for Homeland Security, page to appear.

Gage, A., Murphy, R., \& Minten, B. (2004). Shadowbowl 2003: Lessons learned from a reach-back exercise with rescue robots. IEEE Robotics and Automation Magazine, 11(3), 62-69.

Goddemeier, N., Daniel, K., \& Wietfeld, C. (2012). Role-based connectivity management with realistic air-to-ground channels for cooperative UAVs. IEEE Journal on Selected
Areas in Communications, 30(5), 951-963.

Ishida,H., Nakayama,G., Nakamoto, T.,\&Moriizumi, T. (2005). Controlling a gas/odor plume-tracking robot based on transient responses of gas sensors. IEEE Sensors Journal, 5(3).

Kruijff, G.-J., Tretyakov, V., Linder, T., Pirri, F., Gianni, M., Papadakis,

P., Pizzoli, M., Sinha, A., Pianese, E., Corrao, S.,

Priori, F., Febrini, S., \& Angeletti, S. (2012). Rescue robots at earthquake-hit Mirandola, Italy: A field report. In IEEE International Symposium on Safety, Security and Rescue Robotics (pp. 1-8).

Leptron (2013). Leptron industrial robotic helicopters: Avenger technical specifications.

Murphy, R. (2004). Nsf summer field institute for rescue robots for research and response. AI Magazine, 25(1).

Murphy, R., \& Burke, J. (2008). From remote tool to shared roles. IEEE Robotics and Automation Magazine, 15(4), 39-49.

Murphy, R., Burke, J., \& Stover, S. (2006). Field studies of safety security rescue technologies through training and response activities. IEEEWorkshop on Safety Security Rescue Robots.

Murphy, R. R. (2014). Disaster robotics. Cambridge, MA: MIT Press.

Murphy, R. R., \& Shields, J. (2012). The role of autonomy in dod systems. Technical report, Department ofDefense,Defense Science Board Task Force Report.

Pratt, K. S., Murphy, R., Stover, S., \& Griffin, C. (2009). Conops and autonomy recommendations for vtol small unmanned aerial system based onHurricane Katrina operations. Journal of Field Robotics, 26(8), 636-650.

Ristic, B., Morelande, M., Gunatilaka, A., \& Rutten, M. (2007). Search for a radioactive source: Coordinated multiple observers. In Intelligent Sensors, SensorNetworks and Information, 2007. ISSNIP 2007.3rd International Conference (pp. 239-244).

Russell, R. A., Thiel, D., Devesa, R., \&Mackay-Sim, A. (1995). A robotic system to locate hazardous chemical leaks. In IEEE International Conference on Robotics and Automation.

Scientific, T. (2013).Radeye PRD-ER high-sensitivity personal radiation detectors.

Shrewsbury, B., Henkel, Z., Kim, C. Y., \& Murphy, R. R. (2013). Respond-r test instrument: A summer institute 2013 case study. In IEEE International Symposium on Safety, Security and Rescue Robotics.

Vicente, K. J. (1999).Cognitive work analysis: Towards safe, productive, and healthy computer-based work. L. Erlbaum Associates, Inc.

Woods, D., \& Hollnagel, E. (2006). Joint cognitive systems: Patterns in cognitive systems engineering. Taylor \& Francis Group, Boca Raton, FL: CRC Press.

Zarzhitsky, D., Spears, D. F., \& Spears, W. M. (2005) Swarms for chemical plume tracing. In IEEE Swarm Intelligence Symposium. Journal of Field Robotics DOI 10.1002/rob 